\title{
Estudio del marco normativo colombiano para equinos como vehículos de tracción a sangre
}

\section{Study of the colombian normative framework for horses as blood traction vehicles}

Fecha de recepción: 3 de agosto de 2017

Fecha de aprobación: 27 de diciembre de 2017

Gloria Elena Estrada-Cely ${ }^{1}$

Diego Felipe Pinto-Díaz ${ }^{2}$

DOI: https://doi.org/10.19053/01228420.v15.n1.2018.7758

\section{Resumen}

La investigación permitió realizar un análisis detallado de la normatividad colombiana relacionada con el uso de equinos como vehículos de tracción a sangre, y su particular desarrollo en el municipio de Florencia, departamento del Caquetá; resultó evidente que existe un claro marco jurídico, pero su aplicación es baja y en muchos casos nula, con lo que se ha garantizado la perpetuación de los estados de impunidad del delito de maltrato animal, además de su ausencia de efectividad en términos de transformación social y cultural. Las principales dificultades dentro del proceso fueron el desconocimiento, la falta de manejo efectivo de los lineamientos normativos disponibles y la poca comunicación entre las entidades responsables de su cumplimiento, incurriendo en aparente prevaricato por omisión y franca vulneración al principio constitucional de coordinación administrativa.

Palabras clave: equino; normatividad bienestar animal; tracción a sangre.

\section{Abstract}

This research aimed at analyzing in detail the Colombian regulations concerning the use of horses as blood traction vehicles, and particularly, their development in the municipality of Florencia, Department of Caquetá. It is clear that a legal framework exist, however, its application is rare or sometimes null, thus perpetuating the impunity of animal abuse crimes, and the lack of effectiveness in terms of social and cultural transformation. The main difficulties found were the lack of both knowledge and effective management of the normative guidelines, and the scarce communication

1 PhD. Universidad de la Amazonía (Florencia-Caquetá, Colombia). ORCID: 0000-0003-0576-4432.

2 Universidad de la Amazonía (Florencia-Caquetá, Colombia). ORCID: 0000-0001-6534-251X. 
between the entities responsible for compliance, incurring in apparent malfeasance by omission and frank violation of the constitutional principle of administrative coordination.

Keywords: blood traction; horse; normativity and animal welfare

\section{Para citar este artículo:}

Estrada-Cely GE., Pinto-Díaz DF. Estudio del marco normativo colombiano para equinos como vehículos de tracción a sangre. Ciencia y Agricultura. 2018; 15(1): 69-80. 


\section{Introducción}

La tracción animal se ha convertido en una tecnología cada vez más usada, por ser considerada económica y ecológicamente apropiada para los países en vías de desarrollo; esto en consideración, particularmente, a que no usa combustibles fósiles, con lo que se supone un menor impacto ambiental y reducción de costos, pero conlleva serias repercusiones sobre el bienestar de los animales utilizados.

La Organización Mundial de Sanidad Animal (1) ha definido el término bienestar animal como la capacidad individual de un espécimen para enfrentar su ambiente, que incluye su sanidad, sus percepciones, su estado anímico y otros efectos positivos o negativos que influyen sobre los mecanismos físicos y psíquicos de adaptación.

El uso de equinos como vehículos de tracción a sangre se ha establecido como práctica frecuente, socialmente aceptada en la mayoría de los municipios del territorio nacional, como Florencia, capital del departamento del Caquetá, que cuenta con una importante ubicación geográfica y gran riqueza biológica, pero cuya normatividad actual no contempla ningún tipo de prohibición de esta forma de uso de los animales.

Las crecientes manifestaciones de solidaridad humana con los animales y la ausencia en el país de referentes normativos sobre el empleo de estos como vehículos de tracción a sangre han generado diversas normas, como la Ley 1774 de 2016, "Por medio de la cual se modifica el Código Civil, la Ley 84 de 1989, el Código Penal, el Código de Procedimiento Penal y se dictan otras disposiciones", y ampliado los fundamentos que sustentan la consideración de los animales como parte del ambiente, propiciando una necesaria reformulación de los patrones de relación humano-animal, para lo que se requieren mecanismos sólidos que permitan perspectivas y análisis holistas del contexto, en el marco tanto de los lineamientos éticos como legales que han mediado en esta forma de uso de los animales.

\section{Métodos}

\section{A. Ubicación}

El municipio de Florencia limita por el Norte con el departamento del Huila y el municipio de La Montañita; por el Este, con el municipio de La Montañita; por el Sur, con los municipios de Milán y Morelia, y por el Oeste, con el municipio de Belén de los Andaquíes y el departamento del Huila; cuenta con una extensión total de 2.292 km2, y su cabecera municipal está a $242 \mathrm{~m}$. s.n.,m.

\section{B. Postura metodológica}

La investigación tuvo un enfoque mixto, que, para el componente cualitativo, persiguió lineamientos generales de la teoría fundamentada, desde la cual se relacionan y analizan datos de manera sistemática para desarrollar nuevas teorías o posturas científicas que intentan reflejar la realidad del objeto de estudio. En este método, la recolección de datos, el análisis y la teoría que surgirá de ellos guardan estrecha relación entre sí (3).

El análisis de los lineamientos normativos fue desarrollado desde un referente jurídico dogmático, principalmente, desde donde se considera válido solo aquello sustentado en el derecho positivo, es decir, aquellas leyes, vigentes o no, escritas por el ser humano, entendiendo que la jurisprudencia dogmática proporciona los códigos para descifrar el lenguaje en que se encuentran formuladas las normas, así como los criterios que permiten determinar sus efectos y consecuencias (4).

\section{Implicaciones éticas}

En atención a que para la investigación no se requirió del uso de los animales ni de la participación directa de seres humanos, desde referentes intraespecíficos e interespecíficos, según lo señalan Estrada-Cely y Parra-Herrera (5), no se necesitó aval de un comité de ética o el diligenciamiento de consentimientos informados o acuer- 
dos de confidencialidad.

\section{Resultados y discusión}

\section{A. Marco normativo para el uso de los animales como vehículos de tracción a sangre}

El marco normativo nacional relacionado con los animales utilizados como vehículos de tracción a sangre se encuentra constituido, en primera instancia, por los referentes establecidos en la Constitución Política de Colombia de 1991, que en su Artículo 8 establece como obligación, tanto del Estado como de las personas, la protección de las riquezas culturales y naturales de la Nación, entendiendo dentro de estas a los animales, como componentes estructurales del ambiente, y en el Artículo 79 estipula que todos los colombianos tienen derecho a disfrutar de un ambiente sano, así como a garantizar la protección de este por el Estado.

Según Estrada-Cely y Cedeño-Tovar (6), el ambiente no es solo el espacio en el que se desarrolla la vida de los seres vivos, sino el conjunto de los seres humanos, animales, plantas, objetos, agua, suelo, aire y las relaciones entre ellos; por lo que los equinos que son utilizados como vehículos de tracción animal a sangre, al ser seres vivos, son también parte del ambiente, y es por esto que el Estado debe garantizar que su relación con las demás especies sea la más adecuada y sana posible.

Históricamente, el primer referente normativo relacionado directamente con los animales en Colombia data del año de 1972, con la promulgación de la Ley $5^{\mathrm{a}}$, "Por la cual se provee a la fundación y funcionamiento de Juntas Defensoras de Animales" (7); según su artículo tercero, esta ley tiene como objetivo general promover campañas educativas y culturales tendientes a despertar el espíritu de amor hacia los animales útiles al hombre y evitar actos de crueldad, los maltratamientos y el abandono injustificado; esta ley es un forma representativa de vincular a la comunidad con las autoridades municipales y con los animales y su entorno, y favorecer de alguna forma la consolidación de un cambio cultural de la relación humano-animal.
La Ley $5^{\text {a }}$ fue reglamentada en 1973, por el Decreto 497 (8) de la Presidencia de la República, en el que se indica que las juntas tendrán un carácter educativo que propugnará, a través de sus miembros, crear sentimientos de protección hacia los animales en general y evitar los malos tratos a que puedan ser sometidos. Esta disposición del Estado colombiano expresa un compromiso con los animales, como seres que merecen especial protección, dentro del desarrollo de dinámicas de uso que consideren el bienestar de los animales implicados.

En el mismo año 1973 es promulgada la Ley 23, "Por la cual se conceden facultades extraordinarias al Presidente de la República para expedir el Código de Recursos Naturales y protección al medio ambiente y se dictan otras disposiciones" (9), a cuyo amparo el Presidente de la República expide el Decreto Ley 2811 de 1974, "Por el cual se dictan el Código Nacional de Recursos Naturales Renovables y de Protección del Ambiente" (10), inaugurando el referente de protección de los recursos naturales y de las condiciones para el uso y aprovechamiento de estos. En relación específicamente con los animales, el Decreto Ley establece, en su Artículo 41, el deber del gobierno nacional de ejecutar acciones de control epidemiológico que garanticen la salud de los animales, incluyendo al humano; en este mismo sentido, el Artículo 73 indica la obligación del Estado de garantizar una atmósfera adecuada que brinde garantías para el desarrollo normal de los animales.

En 1979 es promulgada la Ley 9, "Por la cual se dictan Medidas Sanitarias" (11), cuyo objetivo es la protección del medioambientes con el uso y la disposición final de residuos sólidos, entre otros. El capítulo VII de esta Ley, en su Artículo 488, con relación a los procesos de vigilancia y control epidemiológico, indica el deber del Ministerio de Salud de elaborar actividades de prevención de zoonosis, como la encefalitis Equina Venezolana y otras patologías de riesgo, en el caso de los equinos.

En el año de 1986 se expidió el Decreto presidencial 2257, "Por el cual se Reglamentan Parcialmente los Títulos VII y XI de la Ley 09 de 1979, en cuanto a investigación, prevención y control de 
la Zoonosis" (12), que define, en su Artículo 2, el concepto de animales domésticos, como aquellos semovientes de la especie bovina, porcina, ovina, equina, asnal, mular, caprina y canina que, en condiciones normales, puedan convivir con el humano, y su vinculación a referentes de investigación, prevención y control de enfermedades compartidas entre especies, incluida la humana, denominadas genéricamente como zoonosis.

Para el particular caso de equinos utilizados como vehículo de tracción a sangre, el Artículo 28 establece que los propietarios de estos animales tienen la obligación de notificar a las autoridades competentes (que para este caso es el Instituto Colombiano Agropecuario -ICA-) las enfermedades zoonóticas que afecta a los equinos, y en el mismo sentido, el Artículo 33 indica que deben ser vacunados los animales domésticos contra zoonosis inmunoprevenibles. Tal referente legal introduce la esfera de bienestar físico de los animales, en aspectos generales de prevención de enfermedades, al menos para los casos en los que de las mismas se deriven riesgos zoonóticos.

Para profesiones cuyo campo de acción corresponde al uso de los animales, en 1985 el Congreso de la República promulgó la Ley 73, "Por la cual se dictan normas para el ejercicio de las profesiones de medicina veterinaria, medicina veterinaria y zootecnia" (13), en la que, según su Artículo primero, estas profesiones son definidas como de nivel universitario, encontrándose basadas en una formación científica, técnica y humanista con ejercicio en el territorio colombiano. Quince años más tarde, el mismo órgano legislativo promulgó la Ley 576 de 2000, "Por la cual se expide el Código de Ética para el ejercicio profesional de la medicina veterinaria, la medicina veterinaria y zootecnia" (14), en la que se desarrollan, de manera general, los postulados éticos para el ejercicio profesional.

En 1989, el Congreso de la República, ratifica el tema de responsabilidad de protección de los animales, con la promulgación de la Ley 84, "Por la cual se adopta el Estatuto Nacional de Protección de los Animales y se crean unas contravenciones y se regula lo referente a su procedimiento y competencia" (15). Tal referente normativo ofreció las herramientas necesarias para desarrollar estrategias de sensibilización respecto a la condición de sintiencia de los animales, a la vez que ratificó la necesidad de sanciones a quienes vulneraran intencionalmente tales disposiciones.

Sin bien pareciera ofrecer la Ley una postura completamente utilitarista de los animales, en ella se establecen referentes importantes de su consideración como seres sintientes, como el poder optar terapéuticamente por la eutanasia, entendida como muerte sin dolor ni angustia, en los casos de atención de pacientes cuyo estado clínico resulta irrecuperable o incurable, según lo estable del Artículo 19 de la Ley 576 de 2000.

Para el específico referente de uso de los animales, el Congreso de la República promulgó, en 2002, la Ley 769, "Por la cual se expide el Código Nacional de Tránsito Terrestre y se dictan otras disposiciones" (16), en cuyo Artículo 45 establece que los vehículos de tracción a sangre deben portar, en el extremo trasero, una placa reflectiva con identificación. Desde este precedente normativo se establecen los primeros lineamientos para la organización de la actividad, indicando incluso mecanismos de reemplazo para esta forma de uso de los animales, como lo indica el Artículo 98, que estipula referentes para su erradicación, al menos, para los municipios de categoría especial y de primera categoría.

Para el departamento del Caquetá, la Asamblea Departamental expide en el año 2005 la ordenanza 020, "Por la cual se adopta el Código de Policía (Normas de convivencia ciudadana) para el departamento del Caquetá y se dictan otras disposiciones" (17); el documento cuenta con un capítulo específico que trata el tema de la protección y cuidado de los animales, y en su Artículo 64, para el caso de los equinos, indica la prohibición de realizar actos que ocasionen dolor o sufrimiento, así como el deber de mantener las vías pública libres de excretas, y en el Artículo 65 obliga a la creación del coso municipal y un centro de zoonosis donde serán dirigidos los animales decomisados de casos de maltrato, abandono y demás disposiciones del centro de zoonosis. 
En 2008, el Congreso de la República, como medida para mitigar la contaminación ambiental y urbana, promulgó la Ley 1259, “Por medio de la cual se instaura en el territorio nacional la aplicación del comparendo ambiental a los infractores de las nomas de aseo, limpieza y recolección de escombros; y se dictan otras disposiciones" (18); ley que es reglamentada al año siguiente mediante el Decreto 3695, "Por medio del cual se reglamenta la Ley 1229 de 2008 y se dictan otras disposiciones" (19), del Ministerio de Interior y de Justicia, que tiene como objetivo reglamentar el formato, presentación y contenido del comparendo ambiental de que trata la Ley 1259 de 2008, así como establecer los lineamientos generales para su imposición al momento de la comisión de cualquiera de las infracciones sobre aseo, limpieza y recolección de residuos sólidos, que adelante se codifican.

Para el caso de los equinos que se utilizan como vehículos de tracción, resulta relevante lo dispuesto en el Decreto anteriormente citado, en la medida en que establece que los propietarios de estos animales deben hacerse cargo de las deposiciones fecales de sus animales, para que no contaminen, durante sus desplazamientos, las vías públicas y privadas, mitigando con esto los riesgos sobre salud pública. El decreto ofrece, desde esta postura, un referente de responsabilidad sobre los animales que son aprovechados por algunos sectores de la población humana.

Este mismo año es promulgado por la alcaldía de Florencia el Decreto 251, "Por medio del cual se establece para el municipio de Florencia la organización y control para los vehículos de tracción animal" (20), como referente que permite reglamentar y controlar la circulación de vehículos de tracción a sangre en el territorio municipal, y fijar disposiciones relacionadas con los requisitos de uso, carga y tiempos de trabajo, entre otros; sin embargo, resulta cuestionable algunos aspecto del Decreto, como el permitir que personas que hayan cumplido 16 años de edad puedan tener licencia de conducción de estos vehículos y transitar por las calles.

En 2012, el presidente de la República, por medio del Decreto 178, "Por el cual se establecen me- didas relacionadas con la sustitución de vehículos de tracción animal" (21), autoriza la sustitución de vehículos de tracción animal por vehículos automotores para carga, medida que formaliza acciones que fortalecen el bienestar y protección por los animales, para el caso de los municipios de categoría especial y de primera categoría.

Según el Artículo 6 de la Ley 1551 de 2012, “Por la cual se dictan normas para modernizar la organización y el funcionamiento de los municipios" (22), aquellos que superan los quinientos mil habitantes y los cuatrocientos mil s. m. I. v. son de categoría especial, y los que tienen menos de quinientos mil habitantes hasta cien mil uno, con s. m. I. v. comprendidos entre cien mil y cuatrocientos mil COP son de primera categoría; en este orden de ideas, Florencia no es cobijada por las disposiciones legales de prohibición de este tipo de uso de los animales, porque pese a contar con un poco más de 175.407 habitantes, como lo indica el Plan Municipal de Desarrollo (23), no cumple con los s.m.l.v. que indica la norma, lo que la ubica como un municipio de tercera categoría.

En 2013, el Concejo Municipal de Florencia, mediante el Acuerdo 031, "Por medio del cual se crea el Coso municipal en el Municipio de Florencia, Caquetá, y se dictan otras disposiciones" (24), establece la creación del coso municipal, como una dependencia adscrita a la Secretaría de Ambiente y Desarrollo Rural, y que se define como el lugar donde deben ser llevados los animales que se encuentren en vías públicas o privadas, para ser albergados en condiciones de bienestar, en espera de la definición de su situación o destino.

El 2016 se constituyó en el año de los más significativos adelantos en materia del desarrollo normativo en bienestar animal; inició con la promulgación de la Ley 1774, "Por medio de la cual se modifica el Código Civil, la Ley 84 de 1989, el Código Penal, el Código de Procedimiento Penal y se dictan otras disposiciones" (25); con esta ley, los animales abandonan por fin su condición jurídica de cosa, para ser considerados seres sintientes. La norma, además, endurece las penas por maltrato animal, elevando a delito penal esta conducta. Según Contreras (26), la expedición de esta Ley representa un 
parteaguas del derecho animal en Colombia, en la medida en que, a partir de esta, la afectación a este tipo de seres vivos no constituye una infracción por daño a una cosa o a un bien ajeno, sino por el delito de maltrato animal, del cual se deriva un proceso de carácter policivo y judicial (26).

Ese mismo año es promulgada la Ley 1801, “Por la cual se expide el Código Nacional de Policía y Convivencia" (27), que establece en su articulado diversas disposiciones que promueven de forma preventiva la protección contra el maltrato animal. La Ley establece, de manera general, ciertas conductas indebidas en el marco de la relación humano-animal en las zonas urbanas, dentro de las que, para el caso de los equinos utilizados como vehículos de tracción a sangre, se destaca la prohibición de animales deambulando sin control y contaminando con excretas en vías públicas; así mismo, este código, dentro de sus medidas correctivas, establece en su Artículo 180 multas que van desde los 4 hasta 32 salarios mínimos diarios legales vigentes.

El impacto de este referente normativo promovió en el Concejo municipal de Florencia la modificación del Acuerdo 031 de 2013, a través del Acuerdo 021 de 2016, "Por medio del cual se modifican algunas normas relativas a la administración, operación y funcionamiento del Coso municipal, y se dictan otras disposiciones" (28), en cuyo Artículo primero establece que el coso municipal tiene como fin albergar los animales domésticos (felinos, caninos, equinos, bovinos, caprinos, porcinos, ovinos, asnales y mulares) que se encuentren deambulando en las vías públicas o terrenos privados o públicos y que por descuido o abandono de sus dueños o tenedores infrinjan las normas de convivencia ciudadana y el Código Nacional de Tránsito Terrestre.

La adecuada creación y funcionamiento del coso municipal otorga herramientas efectivas para establecer los procesos punitivos contemplados en los referentes legales anteriormente señalados, y para fortalecer la transformación cultural a favor de que el tema del maltrato animal no sea contemplado solo como un delito, sino como una conducta incorrecta desde las éticas de las poblaciones humanas y las moralidades de cada uno de quienes las conforman. Cuestión que ha de tener particular efecto para municipios como Florencia, que, según datos suministrados por el profesional Veterinario de la Secretaría de Ambiente y Desarrollo Rural, de la alcaldía de Florencia, registra en los archivos de la Secretaría de Tránsito la existencia de 441 equinos utilizados como vehículos de tracción a sangre.

\section{B. Las instituciones gubernamentales}

Las instituciones identificadas fueron: del orden nacional, con seccional en el departamento del Caquetá: Policía Nacional, Fiscalía General de la Nación, Procuraduría Ambiental e Instituto Colombiano Agropecuario -ICA-; del orden departamental: Secretaría de Agricultura Departamental, y del orden municipal: Inspección de Policía y Secretaría de Agricultura y Desarrollo Rural.

Policía Nacional (29). Como cuerpo armado de naturaleza civil, la Policía Nacional tiene, según el Artículo 218 de la Constitución Política, la función primordial de mantener las condiciones necesarias para el ejercicio de los derechos y libertades públicas, y para asegurar que los habitantes de Colombia convivan en paz. En razón de ser considerados los animales, particularmente los domésticos, objetos de propiedad y, en general, parte integral del ambiente, recae sobre esta institución la responsabilidad de velar por su cuidado y uso racional. Entre las funciones de la institución se cuenta la de prestar acompañamiento y apoyo a las autoridades administrativas en los casos de maltrato animal, con la respectiva incautación cuando se realicen actividades de verificación y operativos.

En cuanto a programas de protección ambiental que desarrolla esta entidad, enfocados particularmente a equinos, se encuentra el de "Control al maltrato animal", que tiene como finalidad la neutralización del sufrimiento y dolor de los animales en todo el territorio nacional, y el de "Organización comunitaria", dirigido a niños, niñas y adolescentes estudiantes de instituciones educativas, con el fin de incentivar la protección del ambiente.

Según datos oficiales reportados por el grupo de Protección Ambiental y Ecológica del departamen- 
to del Caquetá, en el municipio de Florencia, en el periodo del 10 de agosto de 2011 hasta el 14 de octubre de 2016, se ha reportado seis casos de decomiso o rescate, donde se registran nueve equinos que fueron aprehendidos cuando deambulaban por las calles, y que posteriormente fueron puestos a disposición de la Secretaría de Ambiente Municipal de Florencia; debido a que estos decomisos se realizaron en vías del municipio, no reposan registros de propietarios.

Los reportes de casos de decomisos de animales deambulantes en la ciudad son contradictorios con la realidad evidente en ella, donde con frecuencia y, particularmente, en las noches pueden ser observados gran cantidad de animales recorriendo libremente las áreas pública en búsqueda de alimento, especialmente en bolsas de la basura que con frecuencia rompen, dispersando su contenido; adicionalmente, resulta cuestionable la ausencia de casos de procesos sancionatorios, especialmente con relación al incumplimiento de los referentes normativos relacionados con peso máximo de carga, edades de uso, horarios de circulación, etc.

Fiscalía General de la Nación. En ejercicio de sus funciones, establecidas en el Artículo 250 de la Constitución Política de Colombia 1991, la Fiscalía General de la Nación "está obligada a adelantar el ejercicio de la acción penal y realizar la investigación de los hechos que revistan las características de un delito que Ileguen a su conocimiento por medio de denuncia, petición especial, querella o de oficio, siempre y cuando medien suficientes motivos y circunstancias fácticas que indiquen la posible existencia del mismo". Por lo tanto, se evidencia la vinculación directa de esta entidad estatal con los procesos relacionados con el maltrato animal. Según la página oficial de la Fiscalía General de la Nación (30), esta entidad estatal tiene como misión penalizar los delitos contra la vida, la integridad física y emocional de los animales, consagrados en el artículo 339A del Código Penal.

En la Fiscalía Seccional Caquetá, según respuesta a la información requerida para el desarrollo de esta investigación, no se reportan casos adelantados que vinculen especímenes equinos utilizados como vehículos de tracción, lo cual está en rela- ción directa con la ausencia de casos reportados por la Policía. Sin embargo, durante el proceso de cierre de la presente investigación, fue documentado un caso de decomiso de un espécimen utilizado como vehículo de tracción a sangre, que abortó en la vía pública y cuyo propietario fue detenido y sindicado por el delito de maltrato animal, lo cual se constituye en el primer referente de judicialización de este tipo de delito, reflejo de nuevas perspectivas en las instituciones públicas, en salvaguarda de adecuadas condiciones de uso de los animales.

Procuraduría Ambiental. En relación con la protección animal, la Procuraduría General de la Nación cumple funciones preventivas y de intervención con los procesos administrativos y judiciales, según lo consagrado en los Artículos 277 y 278 del mandato constitucional de 1991, donde la encargan de velar por la protección al ambiente bajo la acción de prevención (31). En conversación sostenida con la Procuradora Judicial y Agraria, Dra. Diana Ortegón Pinzón, el 25 de abril de 2017, ella ilustra sobre la existencia en el departamento de una burbuja ambiental conformada por todos los órganos del Estado con incidencia en el tema ambiental a nivel regional. La secretaría técnica de esta burbuja se encuentra a cargo del Ejército Nacional, seccional Caquetá, y tiene el objetivo central de evaluar temas que afectan el medioambiente. Infortunadamente, el tema de los equinos utilizados como vehículos de tracción a sangre no ha sido discutido hasta el momento. La funcionaria indica, además, la ausencia de reportes de procesos sancionatorios para este particular caso, lo cual resulta altamente cuestionable en atención a los reportes registrados por la Alcaldía de Florencia, desde la entrada en vigencia de la Ley 1774 de 2016; tal omisión de la responsabilidad legal genera impunidad en los 110 casos de equinos decomisados por diferentes causas, dentro de las que, según el reporte, muchas se encuentran relacionadas con estados de maltrato animal.

Instituto Colombiano Agropecuario -ICA-. Según el artículo quinto del Decreto presidencial 4765 de 2008, "Por el cual se modifica la estructura del Instituto Agropecuario, ICA, y se dictan otras disposi- 
ciones" (32), el ICA es la entidad estatal encargada de garantizar una adecuada sanidad agropecuaria en el territorio colombiano, mediante inspección, vigilancia y control directo sobre los especímenes, entre ellos los equinos utilizados como vehículos de tracción a sangre. Para el departamento del Caquetá, el ICA reporta la coordinación de acciones de prevención de la Encefalitis Equina Venezolana, entre cuyas actividades se cuenta la atención a notificaciones de Síndrome Neurológico en Équidos, la vacunación de Équidos, el control de Movilización de Équidos y la vigilancia en las concentraciones de Équidos en el departamento. También, esta entidad indica que adelanta programas de Buenas Prácticas Ganaderas, BPG, e inocuidad en la producción pecuaria, que incluyen publicaciones en pro del bienestar animal y de las buenas prácticas en el uso de medicamentos veterinarios.

Secretaría de Agricultura del Caquetá. En respuesta a la información requerida sobre su actividad misional y funciones administrativas y operativas, la Secretaría de Agricultura del Caquetá informa que en el marco del Plan departamental de desarrollo "Con usted hacemos más por el Caquetá 20162019", contemplado en la Ordenanza 006 del 27 de mayo de 2016 (33), se establece un programa denominado "Caquetá, un entorno saludable para la vida", que tiene como objetivo generar responsabilidad social en la tenencia de animales de compañía y producción y en la protección de la fauna silvestre, mediante campañas de prevención, detección oportuna y control de enfermedades zoonóticas.

Así mismo, la Secretaría de Agricultura departamental es miembro de la junta defensora de animales del Caquetá, y ha promocionado la participación de ciudadanos en las marchas nacionales en contra del maltrato animal. En el mismo sentido, se reporta que la Secretaría de Salud del Caquetá, por medio del Consejo Territorial de Zoonosis, apoya la conformación y realiza seguimiento a las juntas defensoras de animales en todos los dieciséis entes territoriales municipales; sin embargo, vale la pena indicar la ausencia de funcionabilidad y efecto de dichas juntas.
Centro de Justicia Municipal-Inspección de Policía (34). Según la página oficial de la Casa de Justicia (2017), este Centro de Justicia tiene el deber de garantizar el derecho a la justicia a la población colombiana, brindando atención a la resolución de conflictos, con servicios formales e informales de la justicia. En atención a la correspondencia remitida por esta entidad, en la que indica no tener facultad para atender casos de maltrato animal, haciendo claridad en que son los jueces penales o la Fiscalía General de la Nación los que asumen tal competencia, resulta altamente cuestionable el desconocimiento de lo dispuesto en el Artículo 7 de la Ley 1774 de 2016, que dicta: Competencia y Procedimiento. El artículo 46 de la Ley 84 de 1989 quedará así: Artículo 46. Corresponde a los alcaldes, a los inspectores de policía que hagan sus veces, y en el Distrito Capital de Bogotá a los inspectores de policía, conocer de las contravenciones de que trata la presente ley. Para el cumplimiento de los fines del Estado y el objeto de la presente ley, las alcaldías e inspecciones contarán con la colaboración armónica de las siguientes entidades, quienes además pondrán a disposición los medios y/o recursos que sean necesarios en los términos previstos en la Constitución Política, la Ley 99 de 1993.

Lo anterior facilita la impunidad, además de limitar los procesos de transformación social, en razón a la ausencia de investigaciones o seguimientos de casos, además de generan estados de incertidumbre y desconfianza entre los ciudadanos denunciantes de este tipo de delitos o interesados por la protección de los animales.

Secretaría de Ambiente y Desarrollo Rural (35). Según la página oficial de la Alcaldía de Florencia (36), entre las diferentes actividades misionales que desarrolla la Secretaría de Agricultura y Desarrollo Rural se destaca la de velar por la conservación y preservación de los recursos naturales, y entre sus funciones cuenta con las de:

- Dirigir, coordinar, ejecutar o implementar políticas, planes, programas o proyectos locales, regionales y nacionales orientados al desarrollo ambiental. 
- Servicio técnico asistencial al sector agropecuario.

- Dirigir el proceso de planificación del desarroIlo pecuario y ambiental de acuerdo con políticas de los tres niveles del Estado.

- Preservar el patrimonio ecológico municipal.

- Implementar el plan ambiental municipal.

- Direccionar planes, programas y proyectos para la proyección y recuperación de los recursos naturales renovables y las áreas protegidas.
- Fomentar la cultura ambiental ciudadana.

En respuesta a la información requerida, se repor$\tan 109$ casos de decomiso de equinos, en el periodo comprendido entre el 19 de mayo de 2014 y el 15 de enero de 2017; 94 por encontrarse en estado de abandono o deambulando en las calles del municipio; 3, por maltrato; 3, por no llevar la respectiva herradura; 1 , por estar trabajando en malas condiciones; 3 , por no tener la respectiva guía de movilización; 4, por transitar en horas prohibidas; 1, para iniciar tratamiento por enfermedad, y 1 , por estar involucrado en un accidente de tránsito. Todos los animales, posterior a su incautación, fueron remitidos al coso municipal (Tabla I).

Tabla I. Relación casos decomiso, Secretaría de Ambiente y Desarrollo Rural (mayo de 2014 a enero de 2017).

\begin{tabular}{|c|c|c|c|c|}
\hline \multirow{2}{*}{ Motivo decomiso } & \multicolumn{2}{|c|}{ Sexo } & \multirow{2}{*}{$\begin{array}{l}\text { Número de } \\
\text { equinos }\end{array}$} & \multirow{2}{*}{ Destino final } \\
\hline & Hembra & Macho & & \\
\hline Equino abandonado en calle & 39 & 54 & 93 & \multirow{8}{*}{$\begin{array}{l}\text { Entrega a sus propietarios } \\
\text { luego de pagar multas entre } \\
\$ 24.000 \text { hasta } \$ 124.000 \\
\text { pesos, solo } 1 \text { muere por la } \\
\text { gravedad de la enfermedad. }\end{array}$} \\
\hline Maltrato & 1 & 1 & 2 & \\
\hline No llevar herradura & 3 & 0 & 3 & \\
\hline $\begin{array}{l}\text { Trabajando en malas condi- } \\
\text { ciones }\end{array}$ & 2 & 0 & 2 & \\
\hline $\begin{array}{c}\text { No tener guía de moviliza- } \\
\text { ción }\end{array}$ & 1 & 2 & 3 & \\
\hline Transitar en horas prohibidas & 2 & 2 & 4 & \\
\hline Iniciar tratamiento & 0 & 1 & 1 & \\
\hline $\begin{array}{l}\text { Participar en accidente tran- } \\
\text { sito }\end{array}$ & 0 & 1 & 1 & \\
\hline Abandono & 0 & 1 & 1 & Se entrega en adopción \\
\hline Total casos & 48 & 62 & 110 & - \\
\hline
\end{tabular}

Resulta altamente cuestionable la contradicción evidente entre la información reportada por las demás entidades referenciadas y la reportada por la Secretaría de Ambiente y Desarrollo Rural, en franca vulneración al principio constitucional de Coordinación administrativa.

De los procesos remitidos a la Inspección de Policía por la Secretaría de Ambiente y Desarrollo Rural se relacionan dos casos: el primero de un equino que se dio en adopción 130 días después de ser sometido al cuidado y tratamiento por el equipo profesional del Coso municipal, posterior a su decomiso el 11 de mayo de 2016 producto de abandono en las calles de la ciudad; vale la pena indicar que el propietario del equino decomisado solicitó formalmente, por medio de un derecho de petición, la entrega del animal, que fue negada por concepto técnico de la Inspección de Policía. El segundo caso es del equino decomisado el 15 de mayo de 2016, en el marco de una brigada de Salud Animal organizada por la Clínica de Gran- 
des Animales de la Universidad de la Amazonía; el espécimen hembra decomisado registró signos de maltrato animal, según informe técnico del veterinario del coso y presentaba antecedentes de descuido documentado desde brigadas realizadas en años anteriores. Este equino fue trasladado a las instalaciones del coso municipal, donde recibió atención profesional, pero 8 días posteriores a su decomiso, muere. El informe de necropsia y la confirmación de histopatología reportó la presencia de neoplasia maligna de células redondas con metástasis esplénica.

Resulta cuestionable que, según la información suministrada por la entidad, para estos dos casos que fueron remitidos a la Inspección de Policía y con evidencias tangibles de maltrato animal, no se reporte la instauración de los procesos sancionatorios y penales correspondientes ante la Fiscalía, a pesar de haberse desarrollado posterior a la promulgación de la Ley 1774 de 2016.

Por otro lado, al indagar sobre el proceso de valoración del maltrato animal que realizan los profesionales de la Secretaría de Ambiente y Desarrollo Rural, esta entidad reporta que tiene en cuenta los principios establecidos en el Artículo 3 de la Ley 1774 de 2016, esto es, que no sufran hambre ni sed; que no sufran injustificadamente malestar físico ni dolor; que no les sean provocadas enfermedades por negligencia o descuido; que no sean sometidos a condiciones de miedo ni estrés, y que no puedan manifestar su comportamiento natural. Sin embargo, dada la ausencia de un profesional experto o perito para el dictamen clínico y etológico forense en este tipo de casos, la información reportada resulta poco confiable en términos de validez científica y probatoria.

\section{Conclusiones}

Los referentes normativos colombianos relacionados con el uso de equinos como vehículos de tracción a sangre se encuentran claramente desarrollados desde 1972, con la promulgación de la Ley $5^{a}$ y un recorrido histórico de más de una decena de referentes jurídicos, y se consolidan en 2016, con las leyes 1774 y 1801 ; sin embargo, el accionar de las autoridades estatales responsables de su cum- plimiento demuestra un alto nivel de pasividad, incurriendo incluso en estados presuntivos de prevaricato por omisión, en razón tanto a la ausencia de inicio de procesos sancionatorios, como en el compulso de copias de casos a otras dependencias, en franca vulneración al principio constitucional de Coordinación administrativa, además de la perpetuación de los estados de impunidad del delito de maltrato animal y otras infracciones relacionadas directamente con los parámetros establecidos para este tipo de uso de los equinos.

\section{Referencias}

(1) Comisión Europea. Global conference on animal welfare: an OIE initiative. Proceedings. París, 23-25 de febrero de 2004. Oficina de Publicaciones Oficiales de las Comunidades Europeas, Luxemburgo, 2004. 333 p.

(2) Alcaldía de Florencia, Página Oficial. 2016 [En línea] [Consultado el 5 de diciembre de 2016]. Disponible en https://goo.gl/ wDjjOk

(3) Strauss A., Corbin J. (E. Zimmermana). Bases de la investigación cualitativa. Técnicas y procedimientos para desarrollar la teoría fundamentada. Primera edición. Antioquia, Colombia, 2002. 340 p.

(4) Tamayo R., Salmorán R. Dogmática jurídica y teoría moral. Isonomía. Revista de Teoría y Filosofía del Derecho. 1996; (4): 2942.

(5) Estrada-Cely G., Parra-Herrera J. Las implicaciones éticas y bioéticas en la investigación científica. Rev. CES Med. Zootec. 2016; 11(2): 115-118. DOI: http://doi.org/10.21615/cesmvz.11.2.9.

(6) Estrada-Cely G., Cedeño Tovar J. Referente normativo del bienestar animal en Colombia: una mirada al ejercicio profesional de la Medicina Veterinaria y Zootecnia. (En prensa), 2017.

(7) Congreso de la República de Colombia. Ley 5ª/1972. Por la cual se provee a la fundación y funcionamiento de Juntas Defensoras de animales.

(8) Presidencia de la República de Colombia. Decreto 497/1973. Por el cual se reglamenta la Ley $5^{\mathrm{a}}$ de 1972.

(9) Congreso de la República de Colombia. Ley 23/1973. Por la cual se concede facultades extraordinarias al presidente de la República para expedir el Código de Recursos Naturales y protección al medio ambiente y se dictan otras disposiciones.

(10) Presidencia de la República de Colombia. Decreto-Ley 2811/1974. Por el cual se dicta el Código Nacional de Recurso Naturales Renovables y de Protección al Medio Ambiente.

(11) Congreso de la República de Colombia. Ley 9/1979. Por la cual se dictan Medidas Sanitarias. Enero 24 de 1979.

(12) Presidencia de la República de Colombia. Decreto 2257/1986. Por el cual se Reglamenta Parcialmente los Títulos VII y XI de la Ley 09 de 1979, en cuanto a investigación, prevención y control de la zoonosis. 
(13) Congreso de la República de Colombia. Ley 73/1985. Por la cual se dictan normas para el ejercicio de las profesiones de Medicina Veterinaria, Zootecnia y Medicina Veterinaria y Zootecnia.

(14) Congreso de la República de Colombia. Ley 576/2000. Por la cual se expide el Código de Ética para el ejercicio profesional de la Medicina Veterinaria, la Medicina Veterinaria y Zootecnia y la Zootecnia.

(15) Congreso de la República de Colombia. Ley 84/1989. Por la cual se adopta el Estatuto Nacional de Protección de los Animales y se crean unas contravenciones y se regula lo referente a su procedimiento y competencia.

(16) Congreso de la República de Colombia. Ley 769/2002. Por la cual se expide el Código Nacional de Tránsito Terrestre y se dictan otras disposiciones.

(17) Asamblea Departamental del Caquetá. Ordenanza N. ${ }^{\circ}$ 020/2005. Por la cual se adopta el Código de Policía (Normas de Convivencia Ciudadana) para el Departamento del Caquetá y se dictan otras disposiciones.

(18) Congreso de la República de Colombia. Ley 1259/2008. Por medio de la cual se instaura en el territorio nacional la aplicación del comparendo ambiental a los infractores de las nomas de aseo, limpieza y recolección de escombros; y se dictan otras disposiciones.

(19) Ministerio de Interior y de Justicia de Colombia. Decreto 3695/2009. Por medio del cual se reglamenta la Ley 1229 de 2008 y se dictan otras disposiciones.

(20) Alcaldía de Florencia. Decreto 251/2008. Por medio del cual se establece para el municipio de Florencia la organización y control para los vehículos de tracción animal.

(21) Presidencia de la República de Colombia. Decreto 178/2012, Por el cual se establecen medidas relacionadas con la sustitución de vehículos de tracción animal.

(22) Congreso de la República de Colombia. Ley 1551/2012. Por la cual se dictan normas para modernizar la organización y el funcionamiento de los municipios.

(23) Municipio de Florencia. Plan Municipal de Desarrollo. Yo creo en Florencia 2016-2019. Florencia, Caquetá. [En línea] [Consultado el 05 de marzo de 2017]. Disponible en https://goo.gl/yxRIvg

(24) Concejo Municipal de Florencia. Acuerdo 031/2013. Por medio del cual se crea el Coso municipal en el municipio de Florencia, Caquetá, y se dictan otras disposiciones.

(25) Congreso de la República de Colombia. Ley 1774/2016. Por medio de la cual se modifica el Código Civil, la Ley 84 de 1989, el Código Penal, el Código de Procedimiento Penal y se dictan otras disposiciones.

(26) Contreras C. Régimen jurídico de los animales en Chile, Colombia y Argentina (antecedentes, codificación y desarrollo legislativo), Tesis doctoral, Departamento de Administración Pública y Ciencias Históricas y Jurídicas, Universidad Autónoma de Barcelona, 2014.

(27) Congreso de la República de Colombia. Ley 1801/2016. Por la cual se expide el Código Nacional de Policía y Convivencia.
(28) Concejo Municipal de Florencia. Acuerdo 021/2016. Por el cual se modifican algunas normas relativas a la administración, operación y funcionamiento del Coso municipal y se dictan otras disposiciones.

(29) Policía Nacional. Página Oficial. 2017 [En línea] [Consultado el 26 de febrero de 2017]. Disponible en https://goo.gl/V9dDpk

(30) Fiscalía General de la Nación, Página Oficial. 2017 [En línea]. [Consultado el 26 de febrero de 2017]. Disponible en: https:// goo.gl/r3Eq1n

(31) Procuraduría General de la Nación. Página Oficial. 2017 [En línea]. [Consultado el 25 de abril de 2017]. Disponible en https:// goo.gl/Rn2Y96

(32) Presidencia de la República de Colombia. Decreto 4765/2008. Por el cual se modifica la estructura del Instituto Agropecuario, ICA, y se dictan otras disposiciones.

(33) Asamblea Departamental del Caquetá. Ordenanza N. ${ }^{\circ}$ 006/2016. Por medio de la cual se adopta el Plan de Desarrollo Departamental "Con usted hacemos más por el Caquetá 2016-2019" y se dictan otras disposiciones.

(34) Casa de Justicia. Página Oficial. 2017 [En línea] [Consultado el 27 de abril de 2017] Disponible en: https://goo.gl/4zoXmZ.

(35) Secretaría de Ambiente y Desarrollo Rural. Página Oficial. 2017 [En línea] [Consultado el 20 de marzo de 2017]. Disponible en: http://goo.gl/tNYDwE. 